\title{
The spiritual culture of the younger generation - the key to the development of society
}

\author{
Gulnara Tilenbaeva ${ }^{1 *}$, Samara Karabaeva ${ }^{2}$, Nurzada Kambarova $^{2}$, Asanbek Akmataliev $^{3}$, \\ Damirbek Yrazakov², Erkaiym Sharipova ${ }^{2}$, and Rustambek Salimov ${ }^{1}$ \\ ${ }^{1}$ Kyrgyz-Uzbek International University named after B.Sydykov, 723500, Osh, G.Aitiev str., 27, \\ Kyrgyz Republic \\ ${ }^{2}$ Osh State University, 723500, Lenin Avenue, 331, Osh, Kyrgyz Republic \\ ${ }^{3}$ Osh Technological University, 723503, N.Isanov str., 81, Osh city, Kyrgyz Republic
}

\begin{abstract}
Modern practice urgently requires a theoretical analysis of the younger generation spiritual culture formation problems, considering the realities of a modern, dynamically changing society. The research is relevant because today there is a contradiction between the demand for the spiritual potential of the younger generation by society and the real level of the spiritual culture of young people. The desire to find ways to resolve this contradiction determines the scientific problem of our research. In theoretical terms, this is the problem of substantiating the theoretical and methodological foundations of the younger generation spiritual culture development. In practical terms - the search for ways to optimize the processes of the formation of his spiritual culture in the modern period of the society development. One cannot speak about spirituality and morality as a mass social phenomenon regardless of specific conditions that can either hinder or contribute to the broad assertion of their principles. Today our society is going through a difficult period of its development, where crisis phenomena have covered all spheres of life and activities of people. The characteristic features of these phenomena in the spiritual sphere of society are a drop in the proportion of moral values, a decrease in spiritual principles in people's lives. In educational work, operating with general categories of social order, we often leave on the background, and sometimes we simply forget, such fundamental concepts for a person as the fulfillment of one's moral duty, conscience, honor, honesty, decency, mercy, dignity, nobility, goodness.
\end{abstract}

\section{Introduction}

Metastases of immorality and indifference in our society have spread so much that they have created favorable conditions for asocial phenomena. Immoral symbiosis led to the fact that universal and national values began to be violated. The problem of spirituality, morality is an eternal problem.

\footnotetext{
* Corresponding author: bondareva.iana@yandex.ru
} 
This problem was dealt with by the ancient philosophers Socrates, Plato, Aristotle, Seneca; the humanists of the Renaissance Petrarch, Dante, Boccaccio, E. Rotterdam, F. Rable, M. Montaigne; T. More, V. Feltre; representatives of humanistic ethics, subjectivistethical theories, religious and mystical philosophy W. Veit, I. Levin, K. Garnett, A. Smith, D. Hume, A. Rogers, F. Sharp, N. A. Berdyaev, D. Merezhkovsky , N. Minsky, V. Bazarov, A. A. Bogdanov; great thinkers G. Hegel, K. Marx, F. Engels, V. I. Lenin; classics teachers Ya.A. Komensky, D. Lock, J. J. Rousseau, I. R. Pestalozzi, I. F. Herbert, A. S. Makarenko, V. A. Sukhomlinsky, N. K. Krupskaya, S. Freinet and others. In the works that have appeared in recent years, the topic of the formation of the spiritual culture of young people is investigated in the works of Bartosh, Aleksandr [1], Blue, M. [2], Boltaboyev, M.[3], Efremova N.V.[4]; interesting works of Kovalev A.A. Kudaikin E.I.[5], Sharipova, E., Kurbanbayev K.A., Omorkulov A.O.[6], Mardonova, F. B.[7], Murzahalilov K.S.[8], Tatvidze, M. L., Bochoidze, I. G., and Gamkrelidze, E. A.[9] and etc.

In recent years, in our country, less and less is said about the moral education of the younger generation, there is a tendency to transfer the spiritual sphere of the personality of religion, to replace moral values with religious and mythical canons. Hence, the urgency of the problem of the spiritual and moral formation of students in modern conditions becomes obvious.

The problem of youth crime is becoming a factor of threat to the national security of the country, including in a strategic perspective. Child delinquency today has taken a leading place in the list of the most acute problems. In the fight against immoral phenomena, a special role belongs to the true democratization of society, without which it is impossible to overcome disbelief, cynicism, and passivity. However, the process of democratization itself can proceed successfully only in conditions of a healthy moral atmosphere in society, when educated, politically mature, highly moral, and civilly responsible people are involved in this process. In such conditions, democracy itself teaches morality through broad publicity, free discussion of current problems, discoveries, comprehensive public control.

Morality is inextricably linked with social responsibility; its assertion cannot be carried out without moral means. A moral position worthy of a person cannot be selective, limited to one or even several spheres; it must manifest itself always, everywhere, and unswervingly. Thus, one cannot be a conscientious and decent person with a developed sense of justice, high citizenship, without being at the same time a true patriot. Thus, one cannot be a conscientious and decent person with a developed sense of justice, high citizenship, without being at the same time a true patriot. A person who does not respect the national culture, language, traditions of his people, is indifferent to its past, present, and future, is just as spiritless and flawed as an ardent nationalist. Thus, to judge the level and state of morality of a person, society, group, collective, it is necessary to bear in mind the entire set of components that make up their behavioral position. This is an attitude to work, the distribution of labor results, a reaction to the violation of social justice, national feelings and personal dignity of a person, consumer, mismanagement of nature, the wealth of the native land, this is also an attitude to the history of the country, to cultural phenomena of the past and present, care of monuments antiquity; it is concern about children, parents, the elderly, attitude to the traditions and customs of the people, and much more, because the truth about the past is a precondition for the truth about today and tomorrow. The decline in morality led to the trampling of many folk traditions acquired over the centuries. The bearers of lack of spirituality and immorality, permissiveness and criminal acquisitiveness impose on society their perverse system of values, their morality - the morality of triumphant vulgarity. Anti-moral phenomena in our country have reached critical proportions. Obviously, in such conditions, the revival of moral values is the assertion of political honesty, overcoming the encroachment on the state of the people's spirit, on the people's rights to work, life, freedom, justice, remembering that a morally educated person 
is, first of all, a worker who has formed a constant need., engage in labor activity, see its fruits, look for ways to improve it and grow in this activity together with a team of workers. But today many able-bodied citizens of our country are among the unemployed, in schools and universities, work on the labor education of student youth has been weakened.

\section{Materials and methods}

Young people have always faced the problem of moral choice. Today the problem of moral choice in our country has also become aggravated. If earlier all the media, schools, student organizations instilled in schoolchildren that they live in the happiest, richest country, today the picture is different. Students who receive information are quite gloomy, they are sensitive to the state of society. All this in a certain way affects the psyche of young people, forms cynicism, denial of truths. One of the most important tasks of the modern school is to prevent the transition of individual violations of norms in the behavior of a student into persistent shortcomings of his moral development. Teaching collectives today must solve this problem, as we said above, in conditions of instability, instability of society, economic crisis, when cruelty, the power of money, sexual promiscuity, individualism is promoted in the media. All this contributes to the erosion of moral values. A significant part of young people today perceives honesty, disinterestedness, conscience, free labor for the benefit of society as an anachronism.

The student is a social being, he acquires the experience of moral behavior, living in a social environment. He is acutely aware of the modern social and material stratification of society. Social injustice in adolescents' forms aggressiveness, the desire to "make money" in any way. Of great concern today is vagrancy in a child's environment, children with situational behavior, emotional instability, easily succumbing to temptation, with a negative attitude towards school, towards educational influence. Without adjusting the individual development of the above groups of adolescents, it is impossible in modern conditions to develop their moral qualities.

So, the spiritual and moral formation of a student in modern conditions is faced with many problems. This is the insufficient development of the theory of the moral formation of the personality, the non-orientation of many of its provisions on modern social and pedagogical reality, the reassessment of the moral values of society, and much more. The development of a modern concept of man, considering the increasing role of the subjective factor in society, can contribute to the establishment of moral values in our country today. It is necessary that a growing person, as he develops, better understand morality as a sociopsychological phenomenon, its content, the form of rules, the role in society and in personal life. Equally necessary is the development of spiritual culture, awareness of one's own moral attitudes towards people and nature.

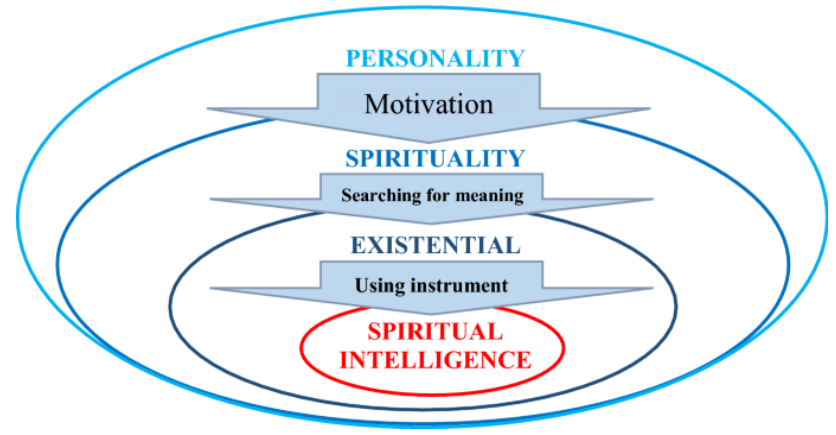

Fig. 1. Theoretical model illustrating the relationship between personality and spirituality. 
For a long time, the problem of moral education in our country was solved at the empirical level with the borrowing of various ideas and points from related fields of knowledge. This state of theory organically blended into the real processes of our society. Today it is necessary to understand many provisions of the theory of moral education. The challenges in this area are complex. It is no coincidence that they provoke heated discussions. There are many problems here. As we have already noted above, they are primarily caused by the fact that today our society is in a state of a rather severe and deep moral crisis.

Great thinkers of the past approached the soul, spirit, spirituality, morality, morality from different positions, linking them with supernatural forces, the world (planetary) mind, the afterlife. But in the heritage of these thinkers, the main thing is not an appeal to the supermind, but to the earthly, behavior, human actions, moral and ethical norms of human society, understanding spirituality as a striving for light, knowledge, as to the sublime, spiritualized, ideal.

"Spirit" is a generic concept of a number of such specific concepts as "good spirit", "evil spirit", "firm spirit", "spirit of the people", "spirituality", "soul", "soulfulness", "humanism"; faith is a certain state of mind of a person; Faith and hope are associated with God, which alleviate suffering for people and mobilize their strength to overcome difficulties, calamities, grief, faith is a problem of religion, truth is not a problem of faith.

Sedankina T.E. notes: "Sincerity is a characteristic of a person, which manifests itself in the ability to empathize and compassion, accepting another person as a value. It is rather difficult to define the concept of spirituality since each science considers this phenomenon from different positions, giving completely different definitions. As noted by B.V. Rauschenbach, spirituality goes beyond rational interpretation, and therefore does not lend itself to strict terminological cutting. First, it should be emphasized that spirituality is understood both in a religious and secular, philosophical and moral context"[10]. "Spirituality" is associated with such concepts as "soul", "spirit", "soulfulness", "humanism", "national spirit", etc. According to Aristotle, the soul provides a person with vital activity, reproduction, sensations, memory, intelligence, etc. etc .; a person becomes just by doing just deeds, moderate, acting in moderation, courageous, acting in dangerous situations and getting used to not being afraid; gets better by exercising his mental strength and abilities. Sincerity is expressed in the actions and deeds of people; assessed in terms of good and evil; healed by the word embodied in the deed, the deed embodied in the word. Faith is a certain state of mind of a person. According to Seneca, we ourselves contain a divine spirit - an observer and guardian of all good and bad; a noble soul is the essence of humanity. The humanists of the Renaissance and subsequent periods highly valued the personality, proclaimed the principles of cheerfulness, activity, the study of nature and all the surrounding reality, a loving attitude towards children, the development of children's thinking, the abilities of students. Great thinkers of the past approached the soul, spirit, spirituality, morality, morality from different positions, connecting them with supernatural morality, reason, supernatural forces, world (planetary) mind, the meaning of life, the afterlife (they associated the "meaning of life" with the attitude of people to one's own life, to the life of other people, with an assessment of human life according to socially significant criteria. Why live, what to live for, what moral guidelines to profess, how to understand a person's vocation, his spiritual and moral obligations to family, science, homeland - without an answer to these and similar questions and today it is impossible to become a full-fledged person). Moral norms, rules and requirements are nothing more than an expression of certain attitudes toward politics, "ideology, the state, the Motherland, labor, nature, people, society, and toward oneself. Each of the listed relationships includes a few norms, rules, and requirements that a person must adhere to, which must form the basis of life and behavior. These norms of behavior not only detail the content of spiritual and 
moral education, but also indicate its versatility. E.K. Sharipova emphasizes that "significant differences between peoples and states in their economic, technological and military power, in the number of population inevitably leads to the fact that one way or another some peoples and states act on the historical arena as a force capable of and striving to impose their the will, culture and language of other peoples and states, and others, respectively, as a party that must in one way or another perceive the influence and pressure emanating from strong and numerous states and peoples. In this case, we are talking about economic and military pressure. However, in no less measure it can refer to cultural and spiritual influence, pressure" [11].

The role of spiritual and moral education in the system of forming a student's personality is great, because following the norms of morality introduces a person to the high spiritual values of society, ennobles all his actions and deeds. Spiritual and moral formation of the student's personality is primarily associated with the solution of a dual task: 1) creating a moral climate in the family, school, guaranteeing the social and moral protection of the child; 2) fostering an active rejection of any form of injustice, any infringement of human dignity, violation of moral norms, fostering a sense of moral duty and responsibility for one's behavior, the behavior of comrades and other team members. Progressive thinkers, outstanding representatives of norms and culture, put forward many ideas related to the problem of morality. A positive analysis and generalization of these ideas is an important stage in the creation of a modern theory of the spiritual and moral formation of students in the pedagogical process.

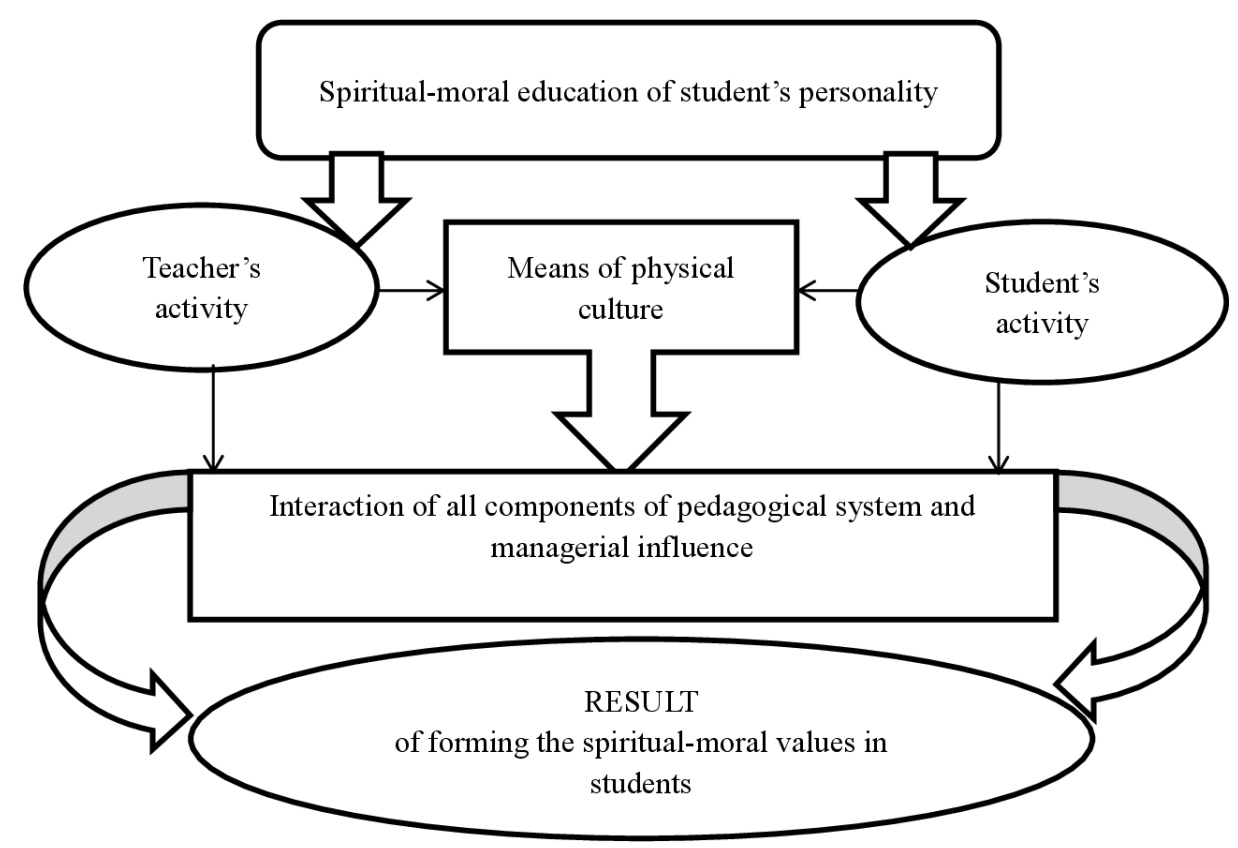

Fig. 2. Spiritual and moral education of students.

Z. Kedeybaeva writes that "a society that has lost a significant part of its ideas and values, while not having a sufficiently clear and predictable idea of its future, even if it realizes the need for transformations, reforms, changes - both external and internal, but does not fully understand neither the goals set for oneself, nor the consequences of their achievement, a society characterized by the presence in it of a significant conflict of values, both at the level of classes, estates and various social groups, and at the level of 
generations, or, in other words, "fathers and children", and finally, a society in which patriotic ideas, moods and feelings have been devalued is undoubtedly in a state of serious threat" [12].

Humanity is the basis of morality, the basis of humanity is universal human morality, which is based on two ethical and philosophical categories: good and evil. Moral norms, rules express certain attitudes of the individual to life, work, homeland, people, to himself. These relations detail various facets of the spiritual and moral education of students. Certain criteria of morality, value-evaluative orientation of children, national selfawareness, citizenship, nationalism, hard work, and the creation of a highly moral school environment are important in the spiritual and moral formation of the student's personality.

Spiritual and moral education has a few components: social, intellectual, emotional, strong-willed. In spiritual and moral education, a system of means and methods is used, the effectiveness of which depends on the observance of a few of pedagogical conditions, starting with taking into account the age and individual characteristics, social experience of children and ending with the complex use in educational work of a combination of various methods and techniques of pedagogical influence on the personality of students.

Spiritual and moral education of students has social, intellectual, emotional, volitional components. We associate education with the social interaction of the teacher and the educated person with their developing attitude. At the same time, the goals set by the teacher act as a product of the student's activity. Assessment of the teacher's activity should be carried out based on the available qualitative shifts in this product, in the consciousness and behavior of the educated person. The moral impulses of the individual as the subjective side of his subject-object relations dictate a certain mode of behavior, which must be consolidated for it to become habitual. Only in this way is the experience of moral behavior formed. It includes conclusions, principles, goals, rules developed by the previous generation. The assimilation of moral experience is an active, creative process. In moral education, the school, to the extent of its capabilities, considers the influence of the family, the social environment, and should strive to make this influence educative. At the same time, she should consider that the social environment today is not conducive to the spiritual and moral formation of schoolchildren. In high school, the correct interpretation of such concepts as honor, dignity, conscience, justice, adherence to principles, duty and responsibility, moral and volitional character traits is of great importance. Because, as $\mathrm{Z}$. Kedeybayeva writes, "degradation and then disappearance of national (or ethnic) selfawareness means, in fact, the spiritual death of the people - the bearer of this self-awareness [13]. Therefore, everything that threatens the destruction of national self-consciousness [14], fraught with the danger of its dissolution in the self-consciousness of other peoples, is a threat to the spiritual security of the people" [15].

\section{Results}

Identifying and implementing the system of means and methods of spiritual and moral education of students, we proceeded from the following provisions of a scientificmethodological, socio-psychological and organizational-pedagogical nature: the moral formation of a person begins from childhood; younger school age has an increased susceptibility to external influences; the spiritual and moral formation of junior schoolchildren primarily occurs in the educational process; moral development is expressed in significant changes in the spiritual and moral world of the child (stable moral behavior, awareness of the moral aspects of their actions, the emergence of internal controlconscience, the development of moral, intellectual, aesthetic feelings); the formation and development of a child's moral relationships is a complex and lengthy process that requires the constant attention of a teacher; there is nothing in the world more complex and richer 
than a human person; the principles of moral education include purposefulness, continuity, efficiency, a combination of requirements with respect, consistency, systematicity, reliance on positive, taking into account the age and individual characteristics of children, the unity of word and deed, personal example.

In spiritual and moral education, many methods and means are used: experience, story, explanation, explanation, teaching, motivation, example, showing, analysis, evaluation, exercise, prohibition, encouragement, punishment, value orientation, persuasion, suggestion, etc. etc. Each method is carried out by means of several techniques that can vary in different ways, considering specific conditions, the level of moral education of schoolchildren, and the general mood of the team. The use of various techniques expands the teacher's ability to creatively approach spiritual and moral education. The effectiveness of the application of methods of spiritual and moral education of schoolchildren depends on the observance of a few pedagogical conditions. These include considering age and individual characteristics, life experience of students, complex use in educational work of a combination of various methods and means, the teacher's possession of various methods and techniques of spiritual and moral formation of schoolchildren, etc.

The theory and methodology of the spiritual and moral formation of the personality is an integral part of social and pedagogical science, the second explores the problems of a person, society from the point of view of optimizing interpersonal, intergroup relations and interactions. Over the past decades, certain successes have been achieved here. However, the modern development of society poses more and more new problems, both in personal and social terms. The solution of these problems requires a rethinking of new realities, taking into account the ongoing changes in the individual-personal consciousness of a person, his behavior, expectations, mastering new patterns of behavior, models of communication, understanding what is and what is due, his role in society, in the structure of personal and hierarchical relations. Such a rethinking can be carried out both at the household and scientific levels. At the scientific level, this happens within the framework of certain theories (new and updated old), models and approaches. Among these models, one should single out psychologically oriented theories, theories of social systems, and cognitive theory. Cognitive theory deals with human thinking, its influence on human behavior, and the solution of individual and social problems. Within the framework of these and other theories, several models of human actions arise psychodynamic, existentialist, humanistic, behavioristic, etc. The psychodynamic model of activity presupposes the possibility of changing, correcting behavior, attitudes, attitudes of a person by influencing his inner world, perception of realities, the nature of relations in contact groups. The influence of social experience, events in the life of an individual on his psyche, on its evolution, on the assessment of the problem of his life becomes possible. The existentialist model in the spiritual and moral formation of the personality focuses on the peculiarities of the perception of a growing person in the system of value-evaluative relations; "subjectobject". The humanistic model proceeds from the intrinsic value of the individual, the individual world of the student, the recognition of the ability to solve many things independently, relying on personal spiritual and practical experience. Denies the rude imposition of a standard of action on the student. Humanism recognizes the human right to freedom, happiness, development and manifestation of one's abilities; believes that human welfare is a criterion for assessing all social phenomena of reality, including the progress of science, production, its meaning, natural boundaries of development. The humanistic type of relations between people presupposes their disinterested basis, the harmony of social interests through the convergence of extremes in the distribution of national wealth. The model of life focuses on the rational aspects of human behavior, the organization of his environment, believes that children can be better understood when they overcome difficulties in educational work, gain confidence, adapting to the environment. 
The behavioral model is based on learning theory, which, unlike the psychodynamic model, focuses on observed stimulus-response behavior. In this case, the actions of the teacher are carried out in the following sequence: observation, measurement, assessment, behavior correction (difficulties are caused by unmotivated, thoughtless, subconscious actions). The interdisciplinary model is based on an integrated approach, an interdisciplinary view of the integrity of nature, knowledge about it.

In the spiritual and moral education of schoolchildren, the personal example of the teacher is important, his ability to explain, explain, explain, convince, present pedagogical requirements that orient children to the correct forms of behavior, the accumulation of positive moral experience, the development of positive motives for actions and deeds, selfdevelopment in order to form socially valuable qualities, overcoming shortcomings of behavior, negative character traits.

In the structure of the teacher's abilities, one can distinguish disposition to children, endurance, self-control (the ability to always, in any environment, in unforeseen circumstances, control oneself, maintain self-control, control one's feelings, temperament, not lose control over one's behavior, one's mental state); didactic, academic, communication, organizational and other abilities. Among these abilities in the educational process, the ability to analyze causes and effects, principles, and actions of students (causal, personal, environmental attribution) is of great importance.

Humanistic pedagogy puts the student in the center, his creative forces, focuses on his personal qualities. She argues that a growing person must create himself and live his life. Man, himself is the creator of himself and his own destiny. The teacher must help him in the choice of basic life guidelines, in solving life conflicts, in the disclosure and implementation of internal mental and intellectual resources. The main principle of humanistic pedagogy is concern for the well-being of the student, love, and respect for him, not idealizing his personality, striving for its versatile development. The main task of upbringing is the formation of the spiritual and moral qualities of the student. The main contradiction that ensures the development of a student is the contradiction between his abilities and the requirements of various types of activity. At the same time, any activity relies on certain abilities, but the requirements imposed by the characteristics of various types of activity often exceed their current level of development of the student, matching the requirements and abilities is the management of the student's development.

The role of spiritual and moral education in the formation of a worthy personality is great. It is primarily associated with the solution of a dual task: with the creation of a spiritual and moral climate in the family, school, in a team that guarantees social and moral protection of everyone and the upbringing of a decently thinking, principled, active person, for whom any form of injustice, infringement of human dignity is unacceptable., violation of social norms of morality; the upbringing of a person who has a sense of moral duty and responsibility for his behavior and the behavior of other members of the team, community.

"Spirituality" is associated with such concepts as "soul", "spirit", "soulfulness", "humanism", "national spirit", etc. According to Aristotle, the soul provides a person with vital activity, reproduction, sensations, memory, intelligence, etc. etc .; a person becomes just by doing just deeds, moderate, acting in moderation, courageous, acting in dangerous situations and getting used to not being afraid; gets better by exercising his mental strength and abilities. Sincerity is expressed in the actions and deeds of people; assessed in terms of good and evil; healed by the word embodied in the deed, the deed embodied in the word. Faith is a certain state of mind of a person. According to Seneca, we ourselves contain a divine spirit - an observer and guardian of all good and bad; a noble soul is the essence of humanity. The humanists of the Renaissance and subsequent periods highly valued the personality, proclaimed the principles of cheerfulness, activity, the study of nature and all the surrounding reality, a loving attitude towards children, the development of children's 
thinking, the abilities of students. Great thinkers of the past approached the soul, spirit, spirituality, morality, morality from different positions, connecting them with supernatural morality, reason, supernatural forces, world (planetary) mind, the meaning of life, the afterlife (they associated the "meaning of life" with the attitude of people to one's own life, to the life of other people, with an assessment of human life according to socially significant criteria. Why live, what to live for, what moral guidelines to profess, how to understand a person's vocation, his spiritual and moral obligations to family, science, homeland - without an answer to these and similar questions and today it is impossible to become a full-fledged person).

In the heritage of these thinkers, the main thing is to appeal not to the supermind, but to earthly behavior, human actions, moral and ethical standards of human society, so that they serve a good cause, nobility, spiritual health of the individual and society. Common in their views is the understanding of spirituality as a striving for light, knowledge, for complete self-affirmation, self-realization, as something sublime, spiritualized, ideal.

The belief that there is a different life, which continues after the disintegration of the body, was characteristic of the model in ancient times, it gave human life on earth a special color. Thinkers such as Plato and Pasidonius were the first to give this view a "philosophical foundation." They argued that our earthly path is only a prelude to eternity. Plato even called the ability to prepare for death the main virtue of a sage.

Barely born, everyone begins to absorb, like a sponge, spiritual and moral norms and learn certain skills and principles of behavior, and then until the very last hour will live, invariably guided by the unwritten laws and rules of the surrounding world. True, not all and not to the same extent are guided by the norms and principles of behavior, moral values accepted in a given environment, and this sometimes sharply distinguishes people from each other, giving reason to judge their spiritual and moral merits, or vice versa, their inferiority. Practical comprehension of the works of thinkers contributes to the identification of the initial methodological guidelines in the development of the problem of the spiritual and moral formation of the personality in modern conditions.

Humanity is the basis of morality. Humanity is based on universal human morality. Moral norms are based on two ethical and philosophical categories: good and evil. Morality is a historical category. Moral norms and requirements in different historical epochs were of a specific nature, reflecting the mores, customs, traditions, culture of their time. The history of the development of morality is the history of the struggle between the new and the old, the progressive against the obsolete (morality tends to lag behind the development of the economy, this is reflected in contradictions in the behavior, actions, actions of people, in their way of life).

Moral norms, rules and requirements are nothing more than an expression of certain attitudes toward politics, "ideology, the state, the Motherland, labor, nature, people, society, and toward oneself. Each of the listed relationships includes a few norms, rules and requirements that a person must adhere to, which must form the basis of life and behavior. These norms of behavior not only detail the content of spiritual and moral education, but also indicate its versatility. The content of spiritual and moral education is undergoing significant changes, in connection with which there is an urgent need to revive universal human values expressed in such ethical categories as conscience, honor, justice, duty, responsibility, spirituality, life, freedom, etc. The right to life and health holy and indestructible; the enduring values that are directly related to spirituality and morality of the individual include freedom and love. Love is a great human happiness. Nowadays, money can buy everything: both conscience and honor, but not love, for it is something special, purely personal, individual. According to E. Fromm, it is love that serves to "humanize people." There is no sacrifice in life that is not justified in the name of love. 
The main feature of the spiritual and moral formation of a student is the formation of his integral personality. Spiritual and moral education cannot be carried out through separate events specially organized by adults from time to time. The necessary synthesis of moral feelings and actions in children can be achieved only when the task of forming humanity in human relations is constantly at the center of attention of the entire upbringing process, which takes place both in the family and at school.

Moral concepts, in comparison with scientific concepts, have their own characteristics that affect their formation in children. These features include, first, personal qualities. It is the selection, recognition of them that cause great difficulties in children, since not a single quality of a person appears in isolation, the same moral concept is manifested in a person in different circumstances, and actions. A spiritual and moral person must have a conscience, goodwill, spirituality. Spiritual education at school is, first, the formation of such qualities as the ability to distinguish between truth and lies, good and evil, and conscientiousness. The spiritual formation of schoolchildren should be based on the humanity of the teacher on caring for children, in deep respect for their human dignity.

Important in the spiritual and moral formation of the student's personality are the definition of the criteria of morality, the value-evaluative orientation of children, the formation of positive motives for learning, actions and deeds, national consciousness, citizenship, patriotism, industriousness, the creation of a moral environment in society, school, the study of the child's social environment, identification and prevention of conflict situations, the teacher's readiness for the moral education of children, both personally and professionally, mutual cooperation between school and family in the moral education of children and students.

The school should be for the student a highly moral environment in which he learns moral norms, is included in real moral relations, and corrects them. The student simultaneously acts both as an object of moral influence and as a subject that creates a moral environment. Mindfulness, generosity, caring, companionable support should become the natural norms of relationships between people at school. First, the bearers of these relations are teachers. For schoolchildren, the pedagogical image is morality, its visual and effective expression. Therefore, the teaching staff should pay special attention to the personal behavior of teachers, considering it as one of the factors of moral improvement of students.

The rules of etiquette should become traditional and natural as regulated and rigidly fixed forms of relationships between people at school. They should be cultivated, brought to perfection. There is no need to be afraid that the external form for schoolchildren will become a screen for internal shortcomings. This will happen only if moral education is replaced by exercises in etiquette.

The school ethical environment should be as broader as possible and continue for students outside of the school. This happens when the school influences the moral family microclimate, works with parents, develops their ethical views and pedagogical ideas. It is important that events, phenomena occurring in society, its problems find a response in school. Acts of solidarity of students and teachers with moral events in the life of our society and progressive humanity seem to push the walls of the school apart, expand the school environment. In creating an educational environment, an important role is played by the object-object space in which the student is located. Order and cleanliness, convenience, and beauty, create a favorable psychological state, disposition to school and people in it.

It is only in a team that a moral environment is formed in which a student develops a relationship of responsible dependence, and, consequently, the best conditions for the formation of the ability to identify with another person. The teacher should devote a lot of time and effort to the creation of a classroom team, plan its development, find the most optimal forms of self-government. Caring for another person is successfully implemented 
in the community of senior schoolchildren and toddlers. It presupposes mutual work and joint activities that bring satisfaction to both parties. Particularly useful is the individual patronage of older schoolchildren over the kids. The main element of the organization of moral activity of students is socially useful work, study, mutual communication.

\section{Conclusions}

Spiritual and moral education of students has several elements: social, intellectual, emotional, strong-willed. We associate education with the social interaction of the teacher and the educated person with their developing attitude. At the same time, the goals set by the teacher act as a product of the student's activity. Assessment of the teacher's activity should be carried out based on the available qualitative shifts in this product, in the consciousness and behavior of the educated person. The moral impulses of the individual as the subjective side of his subject-object relations dictate a certain mode of behavior, which must be consolidated for it to become habitual. Only in this way is the experience of moral behavior formed. It includes conclusions, principles, goals, rules developed by the previous generation.

The assimilation of moral experience is an active, creative process. In moral education, the school, to the extent of its capabilities, considers the influence of the family, the social environment, and should strive to make this influence educative. At the same time, she should consider that the social environment today is not conducive to the spiritual and moral formation of students. In high school, the correct interpretation of such concepts as honor, dignity, conscience, justice, adherence to principles, duty and responsibility, moral and volitional character traits is of great importance

\section{References}

1. A. Bartosh, Threats and Challenges to CSTO (2016) https://doi.org/10.1080/1060586X.2016.1251023

2. M. Blue, A Spiritual Battle for America's Future: Five Takeaways from the Religious Right's Awakening Conference, Right Wing Watch, 19 March 2015, (2015) https://doi/10.1080/20566093.2016.1085243

3. M. Boltaboyev, ISJ Theoretical \& Applied Science, 06 (86), 668-671 (2020) Doi: https://dx.doi.org/10.15863/TAS.2020.06.86.123

4. N.V. Efremova, Islam in the modern world, 16(2), 221-240 (2020) https://doi.org/10.22311/2074-1529-2020-16-2-221-240

5. A.A. Kovalev, E.I. Kudaikin, The correlation between national security and the strategy of state development of Russia (2017) https://doi.org/10.22394/1726-1139$\underline{\text { 2017-4-39-46 }}$

6. K.A. Kurbanbayev, A.O. Omorkulov, ISJ Theoretical \& Applied Science, 02 (58), 2023 (2018) Doi: http://s-o-i.org/1.1/TAS-02-58-6

7. F. B. Mardonova, ISJ Theoretical \& Applied Science, 06 (86), 748-753 (2020) Doi: https://dx.doi.org/10.15863/TAS.2020.06.86.140

8. K.S. Murzahalilov, Islam in the modern world, 15(2), 167-180 (2019) https://doi.org/10.22311/2074-1529-2019-15-2-167-180

9. M. L. Tatvidze, I. G. Bochoidze, E. A. Gamkrelidze, ISJ Theoretical \& Applied Science, 05 (73), 371-374 (2019) Doi: https://dx.doi.org/10.15863/TAS.2019.05.73.54 
10. T.E. Sedankina, IslamicStudies, 13 (1), 135-148 (2020) https://doi.org/10.31162/26189569-2020-13-1-135-148

11. E. Sharipova, Zh. Kedeybaeva, K. Kurbanbaev, Bulletin of Science and Practice 6 (2), 362-368 (2020) https://doi.org/10.33619/2414-2948/51/46

12. Zh.A. Kedeybaeva, Postulate. Amur State University named after Sholem Aleichem (Birobidzhan), 2 (40), 41-45 (2019)

13. E.K. Sharipova, Zh.A. Kedeybaeva, Postulate. Amur State University named after Sholem Aleichem (Birobidzhan), 3 (41), $42-46$ (2019)

14. Zh.A. Kedeybaeva, The role of spirituality in the development of society. VII International scientific and practical conference, Innovative technologies in science and education 31.10 .20

15. Zh.A. Kedeybaeva, Radical threats of spiritual security of the society. VII International scientific and practical conference, Innovative technologies in science and education 27.10.20 